\title{
ZINC - NICKEL COATING AND ITS CHARACTERIZATION BY RF-GDOES AND EDX ANALYSIS
}

\author{
Jiřina VONTOROVÁ, Petra VÁŇOVÁ, Kateřina KONEČNÁ, Karolina SLAMOVÁ, Petr MOHYLA \\ VSB - Technical University of Ostrava, Ostrava, Czech Republic, EU \\ jirina.vontorova@vsb.cz
}

https://doi.org/10.37904/metal.2019.902

\begin{abstract}
Alloy galvanizing with nickel content is a high corrosion and heat resistant coating that meets the high demands of the automotive industry. The plating is galvanic, and the deposited alloy coating is protected by final treatments (passivation and sealing). These treatments cause non-conductivity of the surface coating of the material. The scanning electron microscope (SEM) equipped with the EDX microanalyzer can determine both the coating thickness and its chemical composition, as well as the composition of the base material and another structural component, for example, inclusions. Its drawback is the missing or inaccurate detection of carbon and other light elements. Glow Discharge Optical Emission Spectroscopy (GDOES) measures the thickness and composition of the zinc coating correctly, accurately and with good repeatability. This paper aims to verify the possibilities of the RF-GDOES for analysis of alloy coatings with non-conductive surface treatment. By comparing the results of RF-GDOES analysis and EDX microanalysis carried out using SEM, it was found that both methods provide the same values of the chemical composition of the base material and the alloy coatings, as well as the thickness of the alloy coatings.
\end{abstract}

Keywords: GDOES, profile analysis, zinc-nickel coating, SEM, EDX

\section{INTRODUCTION}

Surface engineering is a significant engineering industry. Its task is to provide corrosion protection and to adjust the exterior appearance [1]. This alters the functional properties of the treated base materials. One of the most widely used corrosion treatments is galvanic or hot-dip galvanizing [2]. The automotive industry's demands for higher corrosion and heat resistance have led to the development of alloy coatings.

The zinc melting temperature [3] is $419^{\circ} \mathrm{C}$ under normal pressure. Zinc alloy with 12 to $15 \%$ nickel melts at temperatures above $700{ }^{\circ} \mathrm{C}$. Therefore, the zinc-nickel alloy coating is often applied as an anti-corrosion protection for steel parts in the automotive engine compartment or other places with an elevated temperature.

The zinc-nickel alloy coating can be deposited from the two basic types of bath. Slightly acidic [4] and alkaline [5]. Both types of baths provide the desired thermal and corrosion protection to the deposited coatings. The advantage of the weakly acid zinc-nickel alloy bath is the possibility of direct plating of cast-iron parts, and a higher deposition rate applied, for example, in the mass plating of geometrically simple parts. The alkaline bath provides a substantially better thickness distribution of the deposited alloy coating. Galvanically deposited alloy coating must be protected by final treatment - passivation and sealing. These treatments cause nonconductivity of the surface layer of the material.

The thickness of the $\mathrm{Zn}$ layer can be accurately determined on the metallographic cut by optical microscopy. However, this method is time-consuming and costly. Therefore, glow discharge optical emission spectrometry is used for its determination. Profile GDOES is used to characterize different surfaces [6], e.g. brake discs [7], organic substances [8] and cementation layers [9]. It is not possible to use traditional GDOES for nonconductive surfaces, but radio-frequency glow discharge optical emission spectroscopy (RF-GDOES) is required [10]. 


\section{EXPERIMENTAL MATERIAL}

The thickness and composition of $\mathrm{Zn}-\mathrm{Ni}$ layers were characterized using two $20 \mathrm{MnB} 4$ (1.5525) rivets (see Figure 1). The chemical composition of the base material was determined after grinding the "Bulk" alloy layer by glow discharge optical emission spectrometry (GDOES) analysis (see Table 1).

Sample 1

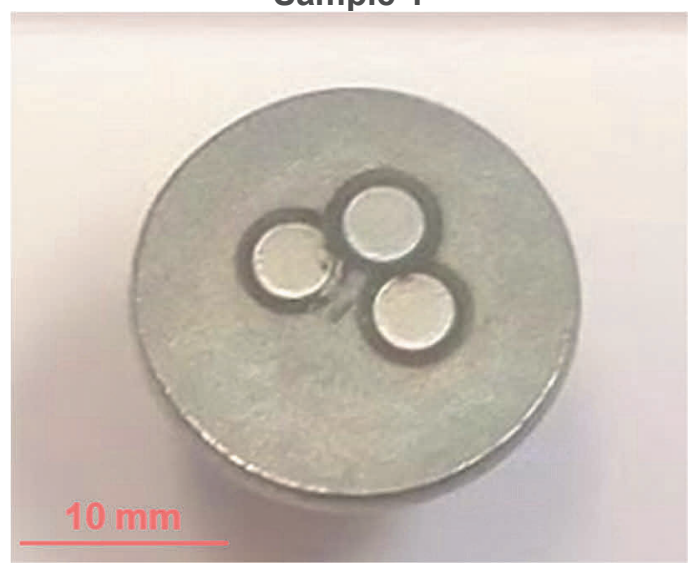

Sample 2

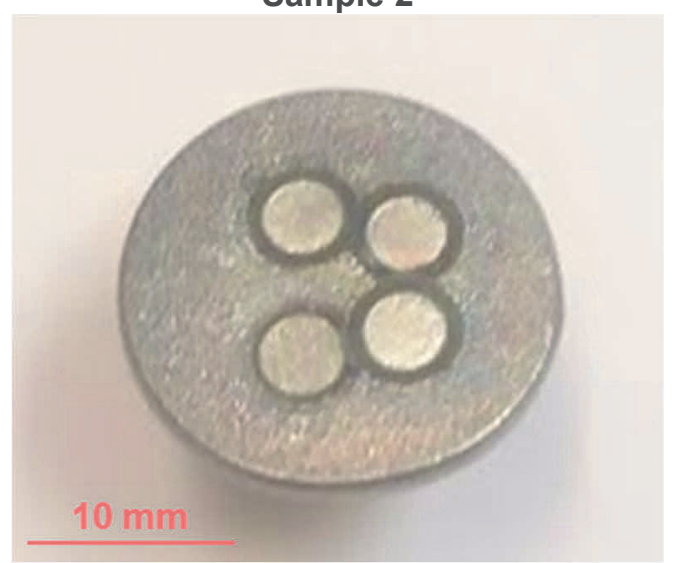

Figure 1 Samples coated with $\mathrm{Zn}-\mathrm{Ni}$

Table 1 The chemical composition of the samples determined by GDOES in wt $\%$

\begin{tabular}{|c|c|c|c|c|c|c|c|c|}
\hline $\mathrm{C}(\%)$ & $\mathrm{Mn}(\%)$ & $\mathrm{Si}(\%)$ & $\mathrm{P}(\%)$ & $\mathrm{S}(\%)$ & $\mathrm{Cr}(\%)$ & $\mathrm{Ni}(\%)$ & $\mathrm{Mo}(\%)$ & $\mathrm{Cu}(\%)$ \\
\hline 0.20 & 0.98 & 0.090 & 0.009 & 0.010 & 0.066 & 0.051 & 0.008 & 0.051 \\
\hline \hline $\mathrm{Ti}(\%)$ & $\mathrm{Co}(\%)$ & $\mathrm{B} \mathrm{( \% )}$ & $\mathrm{Pb}(\%)$ & $\mathrm{V}(\%)$ & $\mathrm{W}(\%)$ & $\mathrm{Zr}(\%)$ & $\mathrm{Al}(\%)$ & $\mathrm{Nb}(\%)$ \\
\hline 0.032 & 0.002 & 0.0017 & $<0.001$ & 0.003 & $<0.001$ & $<0.001$ & 0.047 & $<0.001$ \\
\hline
\end{tabular}

The evaluation of the microstructure was carried out in longitudinal section with respect to the rivet axis by means of an Olympus GX51 optical metallographic microscope - LM (Figure 2). Sample 1 microstructure was ferritic with delta ferrite lines. In the second sample, coarser delta ferrite lines were found in places. The proportion of non-metallic inclusions and grain size in the centre of both parts were comparable.

Sample 1

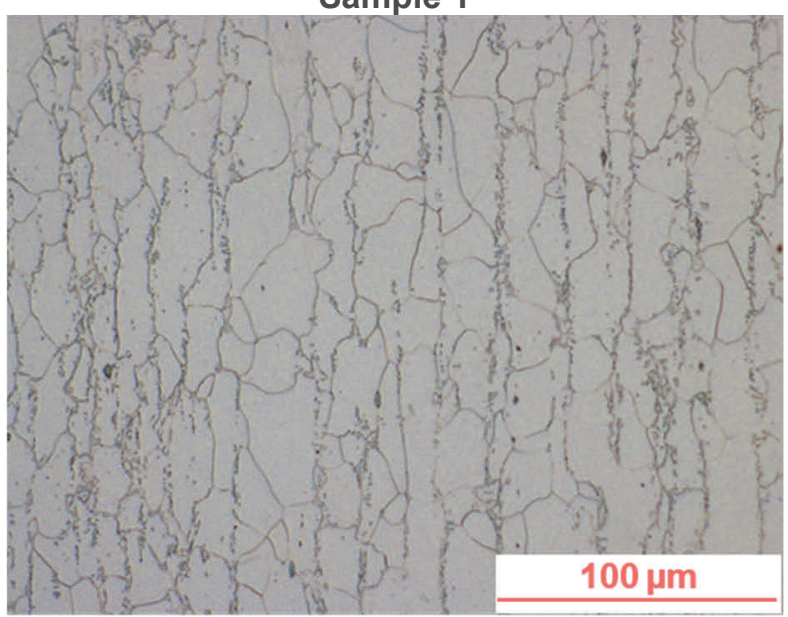

\section{Sample 2}

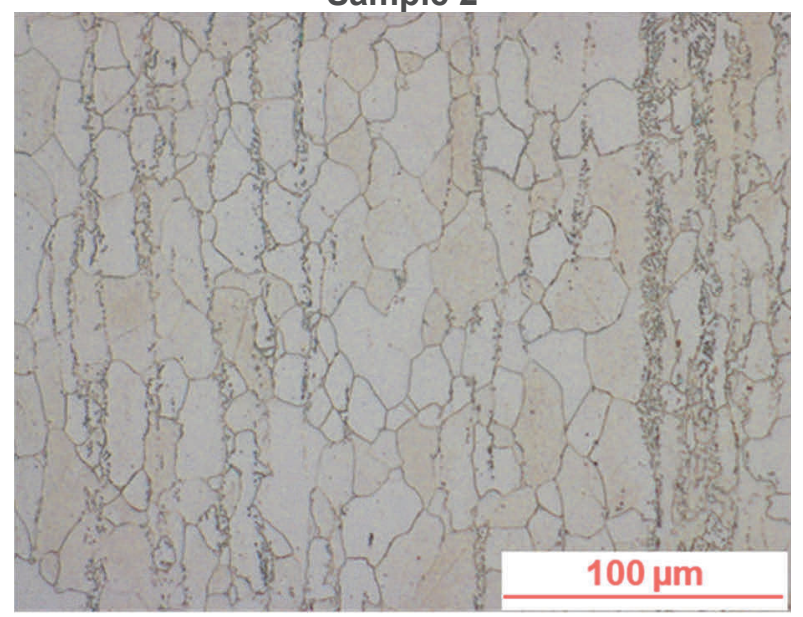

Figure 2 Microstructure of monitored samples (LM) 


\section{EXPERIMENTAL METHODS}

\subsection{Glow discharge optical emission spectroscopy (GDOES)}

GDOES analysis was performed using optical emission spectrometry with glow discharge Spectruma Analytic GMBH (model GDA 750 A). "Bulk" analysis, which was performed under $700 \mathrm{~V}$ and $35 \mathrm{~mA}$ excitation conditions, showed the average chemical composition of the base material of the specimens as well as the chemical composition of the zinc coating after grinding off. The profile analysis (RF-GDOES-QDP), which was used to determine alloy layers thicknesses and their chemical composition, was conducted under the excitation conditions of $800 \mathrm{~V}$ and $2 \mathrm{hPa}$.

\subsection{EDX microanalysis}

EDX microanalysis of the chemical composition of the surface layer and matrix was performed using a JEOL 6490LV scanning electron microscope (SEM) equipped with an energy dispersive X-ray microanalysis INCA (EDX) in the Reflected Electron Mode (BSE) as a spot analysis of the surface layer and a planar analysis of the matrix.

\section{RESULTS AND DISCUSSION}

In the following figures, RF-GDOES-QDP spectra and SEM records are supplemented by the results of EDX microanalysis (Figures 3-6).

In the case of RF-GDOES-QDP analysis (Figure 3 and Figure 5), the y-axis scales of chromium, carbon, and manganese were altered because of their low concentration and hence to make these curves recognizable from each other. Therefore, it is necessary to divide the mass concentrations of these elements from the spectra by 20. Dedusted craters after RF-GDOES-QDP analyses are shown in Figure 1.

Both samples were finished with chromate finishing. This surface causes the material to be non-conductive and therefore requires the use of a high-frequency source in GDOES analysis. This very thin chromium layer is visible on the RF-GDOES-QDP spectra but is not apparent from EDX analysis. Its thickness is 0.5 to $1 \mu \mathrm{m}$.

From the RF-GDOES-QDP spectrum of sample 1, it can be further read that a layer of about $87 \mathrm{wt} \%$ of $\mathrm{Zn}$ and $12 \mathrm{wt} \%$ of $\mathrm{Ni}$ and at a depth of about $14 \mu \mathrm{m}$, the alloy layer no longer exists, and the chemical composition readings correspond to the chemical composition of the base material determined by "BULK" GDOES analysis (see Table 1). An analysis of sample 2 revealed very similar values; only the thickness of the alloy layer is lower (about $12 \mu \mathrm{m})$.

EDX analysis was performed on both samples at eight spots, three of them in the base material - Spectra 6 to 8 (marked Sp. In the figure). The contents found in the base material are almost identical to "BULK" GDOES analysis. Due to the analytical principle, EDX analysis does not provide relevant carbon contents and, because of the low silicon content, information about this element, and these are not included in the quantitative analysis. Spectra 1-3 were measured in the alloy layer and, as shown in the table, the average composition of the alloy layer of sample 1 is $85.6 \mathrm{wt} \%$ of zinc; $12.8 \mathrm{wt} \%$ of nickel and $1.6 \mathrm{wt} \%$ of iron. The average composition of the alloy layer of sample 2 is $85.7 \mathrm{wt} \%$ of zinc; $12.6 \mathrm{wt} \%$ of nickel and $1.8 \mathrm{wt} \%$ of iron. Spectra 4 and 5 correspond to $\mathrm{Zn}-\mathrm{Ni}$ defects with higher oxygen content.

The thickness of the alloy layer of sample 1 is about $13.3 \mu \mathrm{m}$ (see Figure 4), sample 2 is about $12.3 \mu \mathrm{m}$ (see Figure 6). Again, the results show high agreement with RF-GDOES-QDP analysis results.

Samples were measured repeatedly, and a very good match of individual measurements of both GDOES, SEM and EDX analyses was found. 


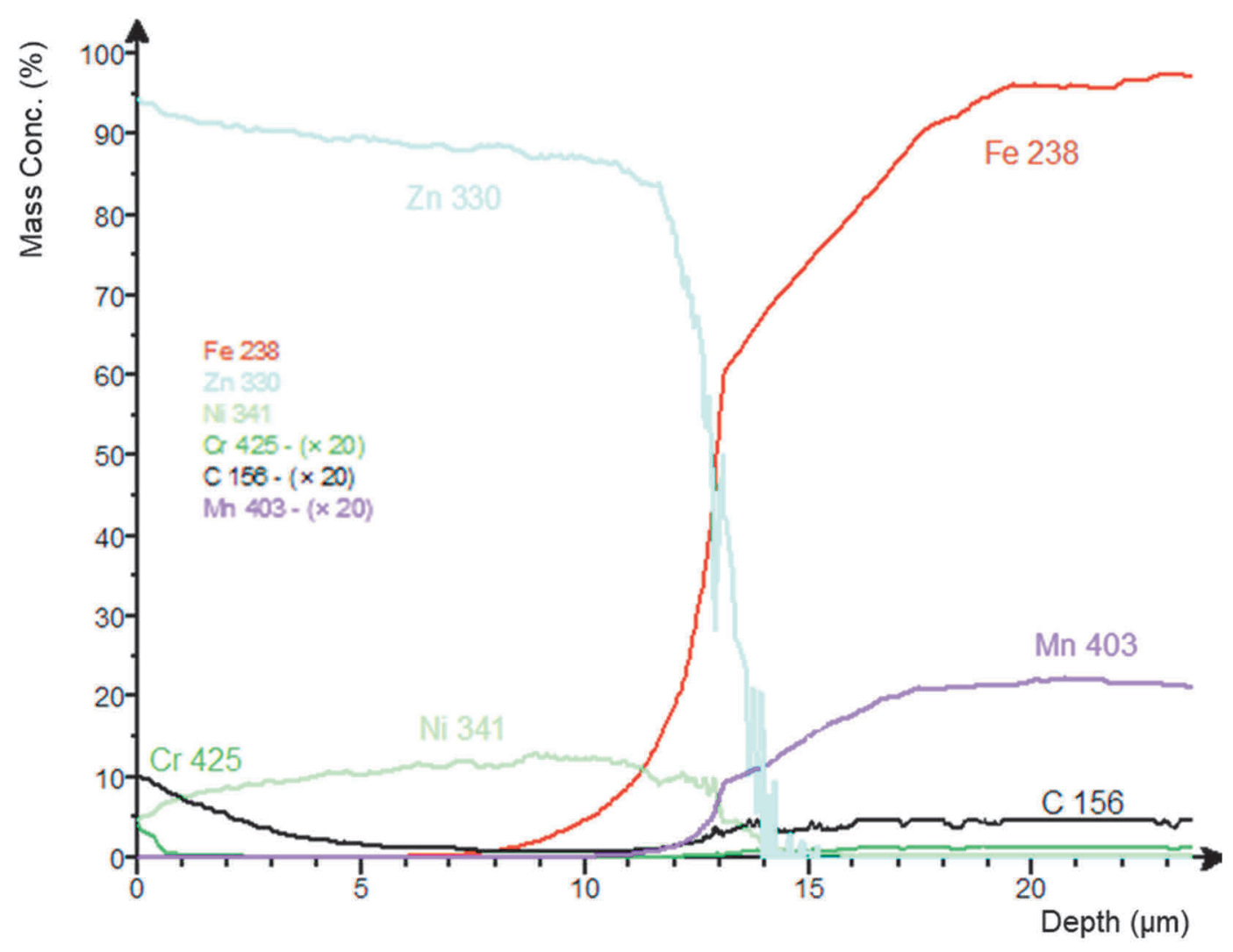

Figure 3 RF-GDOES-QDP spectrum of sample 1

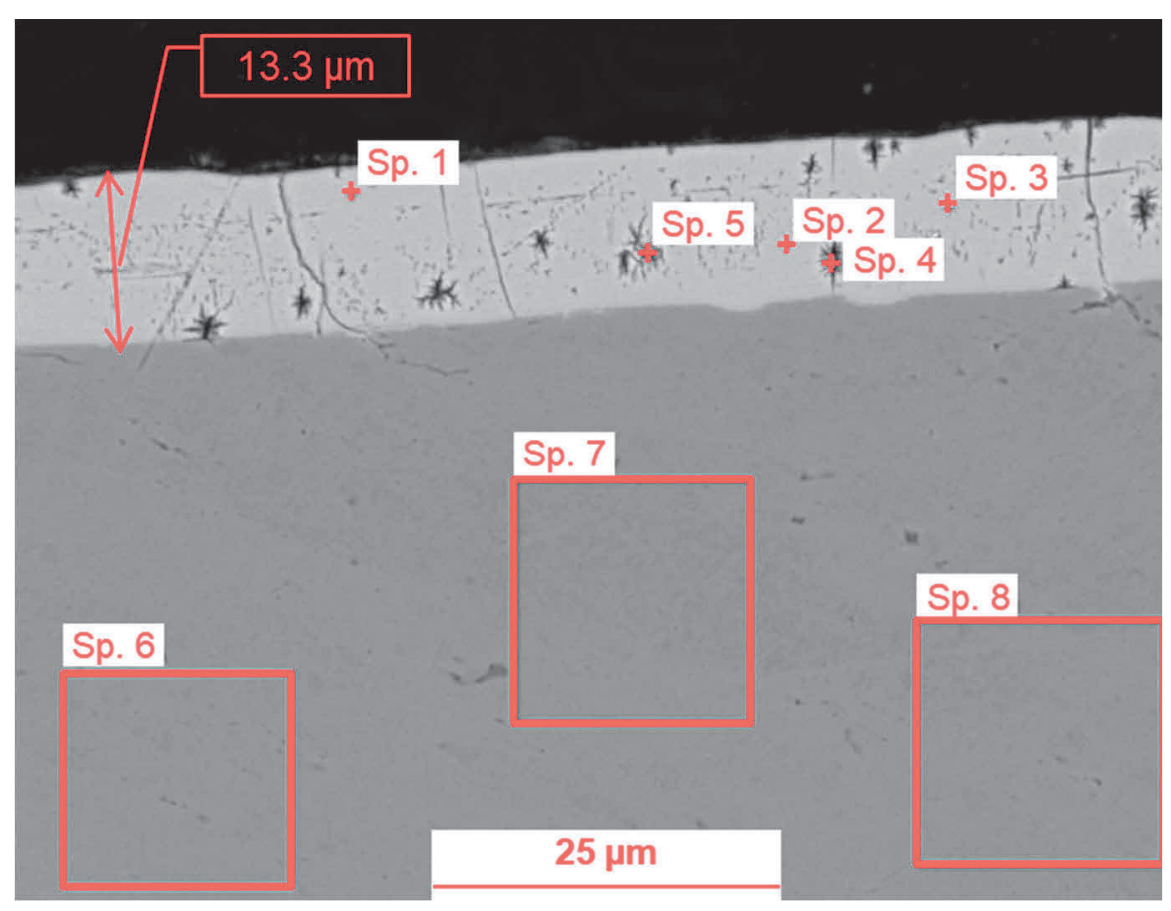

\begin{tabular}{|c|c|c|c|c|c|}
\hline \multirow{2}{*}{ Sp. } & $\mathbf{Z n}$ & $\mathbf{N i}$ & $\mathbf{F e}$ & $\mathbf{M n}$ & $\mathbf{O}$ \\
\cline { 2 - 7 } & \multicolumn{5}{|c|}{ wt. \% } \\
\hline $\mathbf{1}$ & 85.7 & 13.1 & 1.2 & - & - \\
\hline $\mathbf{2}$ & 85.7 & 12.4 & 2.0 & - & - \\
\hline $\mathbf{3}$ & 85.4 & 13.0 & 1.6 & - & - \\
\hline $\mathbf{4}$ & 68.4 & 21.9 & 2.8 & - & 6.9 \\
\hline $\mathbf{5}$ & 75.3 & 17.3 & 2.6 & - & 4.8 \\
\hline $\mathbf{6}$ & - & - & 98.8 & 1.2 & - \\
\hline $\mathbf{7}$ & - & - & 99.1 & 0.9 & - \\
\hline $\mathbf{8}$ & - & - & 98.8 & 1.2 & - \\
\hline
\end{tabular}

Figure 4 SEM image of sample 1 (including EDX chemical composition microanalysis) 


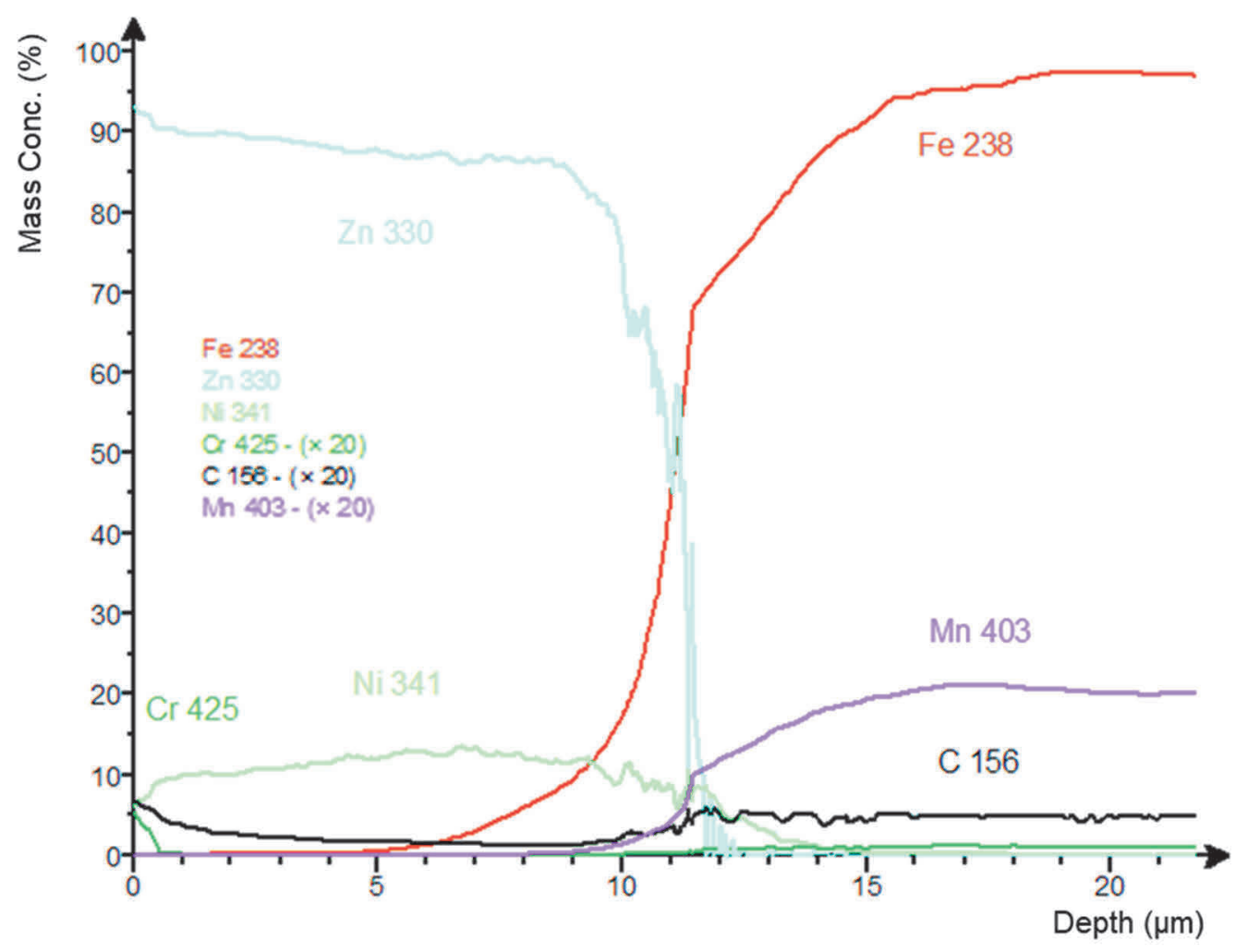

Figure 5 RF-GDOES-QDP spectrum of sample 2

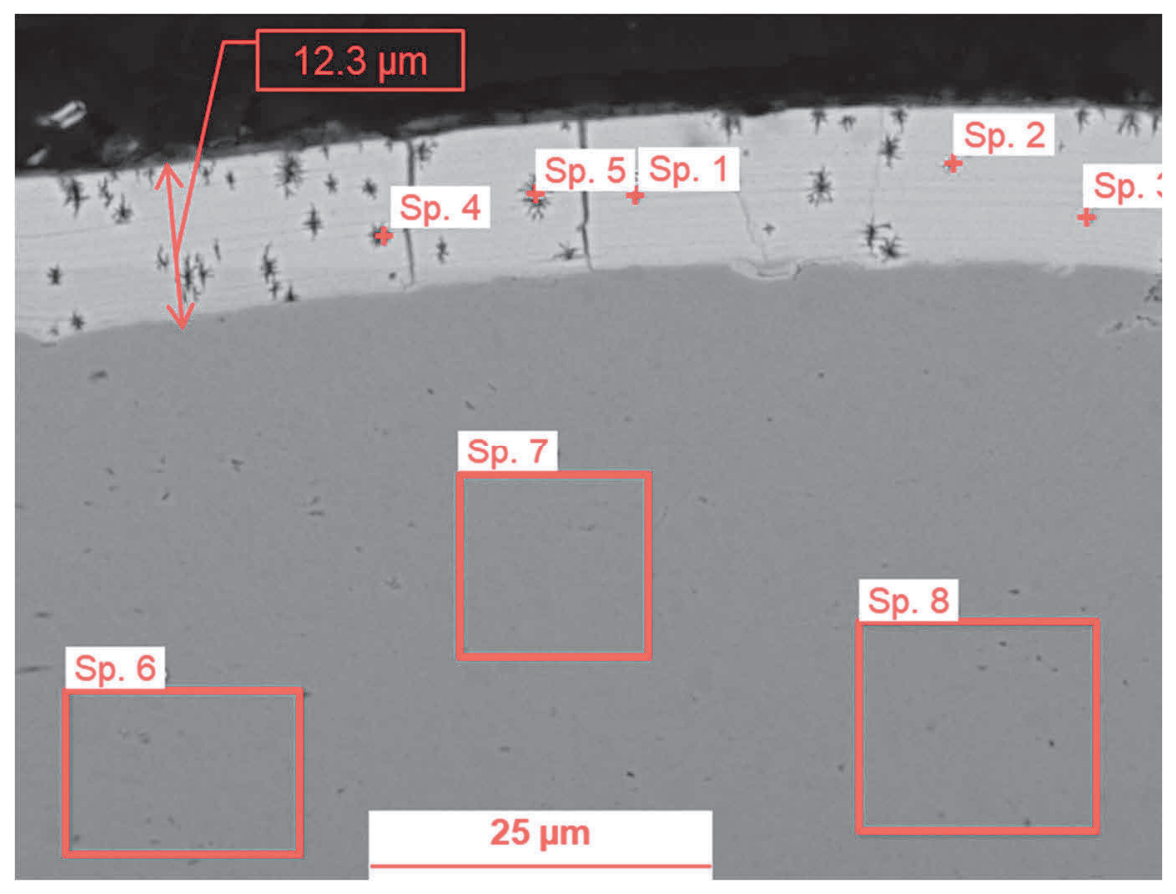

\begin{tabular}{|c|c|c|c|c|c|c|}
\hline \multirow{2}{*}{$\mathbf{S p}$} & $\mathbf{Z n}$ & $\mathbf{N i}$ & $\mathrm{Fe}$ & $\mathrm{Mn}$ & $\mathbf{O}$ \\
\cline { 2 - 7 } & \multicolumn{5}{|c|}{ wt. \% } \\
\hline $\mathbf{1}$ & 85.6 & 12.7 & 1.7 & - & - \\
\hline $\mathbf{2}$ & 85.9 & 12.7 & 1.4 & - & - \\
\hline $\mathbf{3}$ & 85.5 & 12.4 & 2.2 & - & - \\
\hline $\mathbf{4}$ & 84.3 & 12.6 & 2.2 & - & 0.9 \\
\hline $\mathbf{5}$ & 84.3 & 12.9 & 1.7 & - & 1.1 \\
\hline $\mathbf{6}$ & - & - & 99.0 & 1.0 & - \\
\hline $\mathbf{7}$ & - & - & 99.0 & 1.0 & - \\
\hline $\mathbf{8}$ & - & - & 98.9 & 1.2 & - \\
\hline
\end{tabular}

Figure 6 SEM image of sample 2 (including EDX chemical composition microanalysis)

\section{CONCLUSION}

This work aimed was to verify the possibility of using RF-GDOES for the analysis of Zn-Ni alloy coatings and to compare its results with the results of SEM microscopy supplemented with EDX microanalysis. It can be read from the RF-GDOES-QDP spectra that there is a thin layer of chromium on the surface of the samples. 
The alloy coating then reaches a depth of about 12-14 $\mu \mathrm{m}$ and contains about $87 \mathrm{wt} \%$ of $\mathrm{Zn}$ and $12 \mathrm{wt} \%$ of Ni. At a greater depth from the surface, the base material is already found - steel 20MnB4. The standard chemical composition of the base material was confirmed by "BULK" GDOES analysis. The contents determined by EDX analysis of the base material almost coincide with the "BULK" GDOES analysis. Also, the thickness and composition of the alloy layer are not very different from the results of RF-GDOES-QDP analysis. The repeatability of both methods is very good. The comparison of the methods used shows that RF-GDOES-QDP is a suitable method for determining the thickness of the Zn-Ni layer. Differences in RF-GDOES-QDP and SEM results are not statistically significant.

https://doi.org/10.37904/metal.2019.

\section{ACKNOWLEDGEMENTS}

This work was supported by VŠB-Technical University of Ostrava: SP2019/43 „Specific research in the metallurgical, materials and process engineering " and SP2019/27 „Application of structural analysis, mechanical property testing and non-destructive defectoscopy methods at complex characterization of advanced materials".

\section{REFERENCES}

[1] PODJUKLOVÁ, J., SUCHÁNKOVÁ, K., ŠRUBAR, P., KOPANAKOVÁ, S. and HRABOVSKÁ, K. Study of influence corrosive environment on characteristics protective coatings used for long-term corrosion protection of steel substrate, in METAL 2013: 22nd International Conference on Metallurgy and Materials, Ostrava: TANGER, 2013, pp. 953-958.

[2] KUKLíK, V. and KUDLÁČEK, J. Hot-Dip galvanizing of steel structures. 2016. 209 p., DOI: 10.1016/C2014-003512-5.

[3] BROŽOVÁ, S., DRÁPALA, J., KURSA, M., PUSTĚJOVSKÁ, P. and JURSOVÁ S. Leaching refuse after sphalerite mineral for extraction zinc and cobalt. METALURGIJA, Vol. 55, Is.3, P. 497 - 499, 2016. WOS:000372344500054.

[4] BYK, T.V., T.V. GAEVSKAYA and L.S. TSYBULSKAYA. Effect of electrodeposition conditions on the composition, microstructure, and corrosion resistance of Zn-Ni alloy coatings. Surface and Coatings Technology [online]. 2008, 202(24), 5817-5823 [viewed 2019-03-28]. DOI: 10.1016/j.surfcoat.2008.05.058.

[5] TSYBULSKAYA, L.S., T.V. GAEVSKAYA, O.G. PUROVSKAYA and T.V. BYK. Electrochemical deposition of zinc-nickel alloy coatings in a polyligand alkaline bath. Surface and Coatings Technology [online]. 2008, 203(3-4), 234-239 [viewed 2019-03-28]. DOI: 10.1016/j.surfcoat.2008.08.067.

[6] FUKUMURO, N., J. NISHIYAMA, K. SHIGETA, H. TAKAGAMI, S. YAE and H. MATSUDA. Confirmation of hydroxide in electroless cobalt alloy films by GDOES. Transactions of the IMF. 2013, 85(2), 111-112.

[7] VONTOROVÁ, J., V. DOBIÁŠ and P. MOHYLA. Utilization of GDOES for the study of friction layers formed on the surface of brake discs during the friction process. Chemical Papers [online]. 2017, 71(8), 1507-1514 [viewed 2019-03-28]. DOI: 10.1007/s11696-017-0145-4.

[8] LIU, Y., W. JIAN, J.Y. WANG, S. HOFMANN and K. SHIMIZU. Quantitative reconstruction of the GDOES sputter depth profile of a monomolecular layer structure of thiourea on copper. Applied Surface Science [online]. 2015, 331, 140-149 [viewed 2019-03-28]. DOI: 10.1016/j.apsusc.2015.01.065.

[9] VONTOROVÁ, J. and P. VÁÑOVÁ. Determination of carburized layer thickness by GDOES method, AIMS Materials Science, 2018, vol. 5, no. 1, pp. 34-43. WOS:000428531900002.

[10] ESCOBAR GALINDO, R., E. FORNIÉS and J.M. ALBELLA. Compositional depth profiling analysis of thin and ultrathin multilayer coatings by radio-frequency glow discharge optical emission spectroscopy. Surface and Coatings Technology [online]. 2006, 200(22-23), 6185-6189 [viewed 2019-03-28]. 